\title{
Correlation between Hopelessness and Different Levels of Depression among Adolescents
}

\author{
Aditi Bansal $^{1 *}$
}

\section{ABSTRACT}

In this study, the investigator tired to find the correlation of hopelessness with four levels of depression, i.e. normal, mild, moderate and severe depression. Data was collected from a sample of 200 adolescents using two psychological tests and were evaluated as per norms mentioned in the manual; the sample was categorized according to the level of depression. Then correlation between hopelessness and the various levels of depression was calculated using Pearson's product moment correlation which concluded as, there exists a positive correlation between the hopelessness and mild, moderate and severe depression. In other words with the increase in hopelessness, the depression also increases and vice versa.

Keywords: Hopelessness, Adolescents and Depression.

Adolescence generally extends from 13 to 19 years of age and is referred as a stormy period of life. It acts as a bridge between childhood and adulthood. During this stage many sort of developments takes place, like physical, mental, social and emotional. Puberty plays a very vital role in adolescence, which leads to sexual maturity. Erick Erickson in his psychosocial stages marked this stage as fifth stage i.e. Ego Identity versus Role Confusion. There are many sorts of pressures which an adolescent faces it may be peer pressure, social, psychological and even from family. This leads to the problem of depression. And depression is very much common in adolescents. Depression is a state of mind, in which an individual feels sad, worthless and is not able to live in a normal way of life. According to DSM-IV a depressed person loses the interest in the previously liked activities, faces change in sleep patterns which may insomnia or hypersomnia, change in appetite, lack of energy and concentration, self loathing, and even leads to suicidalilty. Hopelessness is a condition, when there is no hope i.e. a situation beyond optimism. In other words, where there is no possibility of being solved or sorted out. It is negative in nature, losing hope, control and confidence for something in future. This may give rise to anti-social behaviors and even depression.

\footnotetext{
${ }^{1}$ Research Scholar, Dept. of Education, Panjab University, Chandigarh, India *Responding Author

(C) 2016 A Bansal; licensee IJIP. This is an Open Access Research distributed under the terms of the Creative Commons Attribution License (http://creativecommons.org/licenses/by/2.0), which permits unrestricted use, distribution, and reproduction in any Medium, provided the original work is properly cited.
} 


\section{Correlation between Hopelessness and Different Levels of Depression among Adolescents}

\section{Objectives:}

1. To study the relationship of hopelessness with normal range of depression.

2. To study the relationship of hopelessness with mild depression.

3. To study the relationship of hopelessness with moderate depression.

4. To study the relationship of hopelessness with severe depression.

\section{Hypotheses:}

1. There exist a significant correlation between hopelessness and normal range of depression.

2. There exist a significant correlation between hopelessness and mild depression.

3. There exist a significant correlation between hopelessness and moderate depression.

4. There exist a significant correlation between hopelessness and severe depression.

\section{METHOD}

\section{Sample:}

A sample of 200 adolescents was selected randomly, studying in eight educational institutions located in Bathinda. Then they were categorized as adolescents with normal, mild, moderate and severe depression.

\begin{tabular}{|l|l|}
\hline Level of Depression & No. of Adolescents \\
\hline Normal range of Depression & 39 \\
\hline Mild Depression & 56 \\
\hline Moderate Depression & 64 \\
\hline Severe Depression & 41 \\
\hline Total & $\mathbf{2 0 0}$ \\
\hline
\end{tabular}

\section{Research Design:}

To study the correlation between hopelessness and different levels of depression among adolescents studying in various educational institutes in Bathinda. The data was collected using two different psychological tests and were evaluated according to the norms mentioned in the manual, the sample was categorized as adolescents with normal, mild, moderate and severe depression: then correlation between hopelessness and different levels of depression was calculated using Pearson's product moment correlation.

\section{Test Tools:}

The following tools were used in the present study to collect the data:

a) Zung Self-Rating Depression Scale (1965).

b) Beck Hopelessness Scale (1988).

\section{Statistical Techniques:}

The tabulated data was analyzed and interpreted by using Pearson Product Moment Correlation.

(c) The International Journal of Indian Psychology, ISSN 2348-5396 (e) | ISSN: 2349-3429 (p) | 190 
RESULTS AND DISCUSSION

To test hypothesis number 1:

Table 1:

\begin{tabular}{|l|c|l|}
\hline Variable & Correlation Coefficient & Level of Significance \\
\hline $\begin{array}{l}\text { Hopelessness and normal } \\
\text { range of depression. }\end{array}$ & 0.15211 & Not Significant \\
\hline
\end{tabular}

As shown in table 1, the coefficient of correlation between Hopelessness and normal range of depression is 0.15211 , which is not significant at any level of significance.

Therefore, the first hypothesis that, "There exist a significant correlation between hopelessness and normal range of depression” is rejected.

To test hypothesis number 2:

Table2:

\begin{tabular}{|l|c|l|}
\hline Variable & Correlation Coefficient & Level of Significance \\
\hline $\begin{array}{l}\text { Hopelessness and mild } \\
\text { depression. }\end{array}$ & $0.254525^{*}$ & ${ }^{*} \mathrm{p}<0.05$ \\
\hline
\end{tabular}

As shown in table 2, the coefficient of correlation between Hopelessness and mild depression is 0.254525 , which is significant at 0.05 level of significance.

Therefore, the first hypothesis that, "There exist a significant correlation between hopelessness and mild depression” is accepted.

To test hypothesis number 3:

Table 3:

\begin{tabular}{|l|c|l|}
\hline Variable & Correlation Coefficient & Level of Significance \\
\hline $\begin{array}{l}\text { Hopelessness and moderate } \\
\text { depression. }\end{array}$ & $0.380183^{* *}$ & $* * \mathrm{p}<0.01$ \\
\hline
\end{tabular}

As shown in table 3, the coefficient of correlation between Hopelessness and moderate depression is 0.380183 , which is significant at 0.01 level of significance.

Therefore, the first hypothesis that, "There exist a significant correlation between hopelessness and moderate depression” is accepted.

\section{To test hypothesis number 4:}

Table 4:

\begin{tabular}{|l|c|l|}
\hline Variable & Correlation Coefficient & Level of Significance \\
\hline $\begin{array}{l}\text { Hopelessness and severe } \\
\text { depression. }\end{array}$ & $0.705554^{* *}$ & $* * \mathrm{p}<0.01$ \\
\hline
\end{tabular}

As shown in table 4, the coefficient of correlation between Hopelessness and severe depression is 1 , which is significant at 0.01 level of significance.

(C) The International Journal of Indian Psychology, ISSN 2348-5396 (e) | ISSN: 2349-3429 (p) | 191 


\section{Correlation between Hopelessness and Different Levels of Depression among Adolescents}

Therefore, the first hypothesis that, “There exist a significant correlation between hopelessness and severe depression” is accepted.

\section{CONCLUSION}

1. Hopelessness is positively correlated to depression that is with the increase in hopelessness, depression also increases.

2. This can be concluded that hopelessness is strongly correlated to Mild, moderate and severe depression. Hopelessness leads to depression and vice versa.

\section{Acknowledgments}

The author appreciates all those who participated in the study and helped to facilitate the research process.

\section{Conflict of Interests}

The author declared no conflict of interests.

\section{REFERENCES}

Anyan, F. \& Hjemdal, O. (2016). Adolescent stress and symptoms of anxiety and depression: Resilience explains and differentiates the relationships. Journal of Affective Disorders,203,213-220.

Ayyub. et.al, (2012). The relationship of personal growth initiative, psychological well-being, and psychological distress among adolescents. Journal of Teaching and Education. 1(6), 101-107.

Beck A.T. (1988). Beck Hopelessness Scale. The Psychological Corporation.

Calvete,E., Villardon,L \& Estevez, A. (2008). Attributional style and depressive symptoms in adolescents: An examination of the role of various indicators of cognitive vulnerability. Behaviour Research and Therapy, 46(80, 944-953.

Chattopadhyay, et.al, (2010), Depression at risk, vulnerable and normal adolescents: A comparison of mental health.JHP.5 (1), 27-35.

Cruz, C. et.al.,(2014). Anxiety and depression in adolescents with hostile behavior. Atencion Primaria, 46,107-111.

Dilek Kilic., et.al, (2011). The effect methods to cope with stress by high school students on hopelessness and self-esteem. Health MED. 5(6), 1573-1579.

Fanaj,N. et.al.,(2015). Depression, Anxiety, Hopelessness and Self-esteem in a Clinical Sample of Adolescents in Kosovo. European Psychiatry, 30,1189.

Fanaj,N., Melonashi, E \& Shkembi, F. (2015). Self-esteem and Hopelessness as Predictors of Emotional Difficulties: A Cross-sectional Study among Adolescents in Kosovo. Procedia-Social and Behavioral Science, 165,222-233.

Grano,N. et.al.,(2016). Community-oriented family-based intervention superior to standard treatemnet in improving depression, hopelessness and functioning among adolescents with psychosis-risk symptoms. Psychiatry Research,237,9-16.

(C) The International Journal of Indian Psychology, ISSN 2348-5396 (e) | ISSN: 2349-3429 (p) | 192 


\section{Correlation between Hopelessness and Different Levels of Depression among Adolescents}

Ingram, R. (2016). Depression. Encyclopedia of Mental Health, 2,26-33.

Kalaiyarasan, M. \& Solomon (2014), Mental health among adolescents. Natural and Social Sciences. 2(8), 27-32.

Kalaiyarasan, M. \& Solomon. (2014), Mental health among adolescents. Natural and Social Sciences. 2(8), 27-32.

Krug, S. et.al., (2016). Family functioning mediates the association between parental depression and low self-esteem in adolescents. Journal of Affective Disorders, 203, 184-189.

Metalsky, G. et.al.,(1997),The Hopelessness Depression Symptom Questionnaire.Cognitive Therapy and Researh.21(3),359-384.

Metalsky, G.,et.al, (1993). Depressive reactions to failure in a naturalistic setting: A test of the hopelessness and self-esteem theories of depression. Journal of Abnormal Psychology, 102, 101-109.

Midley, N. et.al., (2015). Beyond a diagnosis: The experience of depression among clinicallyreffered adolescents. Journal of Adolescence, 44,269-279.

Mumthas, et.al. (2014). Psycho-Social Problems of Adolescents at Higher Secondary Level. Guru Journal of Behavioral and Social Sciences. 2(1), 252-257.

Naranjo, C.R. \& Cano, A.(2016). Daily stress and coping styles in adolescent hopelessness depression: Moderating effects of gender. Personality and Individual Differences,97,109-114.

Needles, D. J., et.a, (1990). Positive life events, attributional style, and hopelessness: Testing a model of recovery from depression. Journal of Abnormal Psychology, 99, 156-165.

Schleider,J.L. et.al.,(2016). Reducing risk for anxiety and depression in adolescents: Effects of a single-session intervention teaching that personality can change. Behaviour Research and Therapy,87,170-181.

Seligman, M. (1992). Helplessness: On depression, development, and death. San Francisco: Freeman.

Spangler, D. L., et.al.,(1993). Evaluating the hopelessness model of depression: Diathesis-stress and symptom components. Journal of Abnormal Psychology, 102, 592-600.

Sun, J. et.al., (2015). Correlates of comorbis depression, anxiety and helplessness with obsessive-compulsive disorder in Chinese adolescents. Journal of Affective Disorders, 174,31-17.

Votz, Z., Haeffel, G., Joiner T. E. \& Wagner, K.D. (2003). Reducing hopelessness: the interaction of enhancing and depressogenic attributional styles for positive and negative life events among youth psychiatric inpatients. Behaviour Research and Therap,41,11831198.

Wahed,W.Y.A. \& Hassan, S.K.(2016). Prevalence and associated factors of stress, anxiety and depression among medical fayoum university students. Alexandra Journal of Medicine.

Wang,Y. et.al,(2015). Role of depression severity and impulsivity in the relationship between hopelessness and suicidal ideation in patients with major depression. Journal of Affective Disorders,183,83-89. 


\section{Correlation between Hopelessness and Different Levels of Depression among Adolescents}

Willburn. et.al, (2005). Stress, Self-esteem and Suicidal ideation in late adolescents. Research Gate Adolescence, Libra Publishers. 40(157) 32 - 45.

Zung, W.W. (1965). A Self-rating Depression Scale. Archives of General Psychiatry.12,63-70.

How to cite this article: A Bansal (2016), Correlation between Hopelessness and Different Levels of Depression among Adolescents, International Journal of Indian Psychology, Volume 4, Issue 1, No. 79, ISSN:2348-5396 (e), ISSN:2349-3429 (p), DIP:18.01.100/20160304, ISBN:978$1-365-56745-2$ 